\title{
Comparison of Sit and Reach Test, Straight Leg Raise Test and Visual Analogue Scale When Applying Static Stretching and Mulligan's Two Leg Rotation in Young Adults with Hamstring Shortness
}

\author{
Ji Hoon Lee', Ji Young Kim', Hye Sun Kim', A Young Lee', Hyoung Won Lim² \\ 'Department of Physical Therapy, College of Health Science, Student of Dankook University, Cheonan; ${ }^{2}$ Departmet of Physical Therapy, College of \\ Health Science, Dankook University, Cheonan, Korea
}

Purpose: This study compared the effects of Static stretching and Mulligan's Two-leg rotation about the Hamstring flexibility, Hip range of motion, and pain.

Methods: The subjects were allocated randomly into two groups: Static stretching group $(n=13)$ and Mulligan's two leg rotation group $(n=14)$. The study was designed with stretching protocols for four minutes and thirty seconds per day five times a week for three weeks in total. Measurements, including the Sit and reach test, Active/Passive Straight leg raise, and Visual analogue scale, were conducted before and after the intervention. The data were analyzed using a paired t-test and independent t-test.

Results: The flexibility of the two leg rotation group was higher than the static stretching group after the intervention. The post-sit and reach test value of the two leg rotation group was significantly higher than the pre-sit and reach test value of the static stretching group. In addition, the variance of the sit and reach test of the two leg rotation group was significantly higher than that of the static stretching group.

Conclusion: These results showed that two leg rotation techniques have a positive effect on the changes in the sit and reach test and active straight leg raise test. Two leg rotation techniques can be recommended as a self-stretching and easier way to stabilize the lumbopelvic rhythm, reduce the stiffness of the muscle and relieve pain. This is effective in preventing muscle damage, enabling muscle relaxation and reducing the risk of injury to the spine during daily lives and in sports activities.

Keywords: Mulligan's two leg rotation, Static stretching, Hamstring shortness

\section{서 론}

뒤넙다리근은 엉덩관절 폄과 무릎관절 굽힘을 담당하는 근육으로 이 중 넙다리두갈래근의 짧은 갈래를 제외한 모든 근육은 궁둥뼈 결 절에 부착되어 있으며 골반과 척추에 많은 영향을 미친다.' 대부분의 스포츠 활동이나 보행 시 초기 디딤기 동안 뒤넙다리근이 원심성수 축을 하며 다리의 에너지를 흡수하기 때문에 많은 하중이 실려 부상 률이 높아지게 된다.2,3 뒤넙다리근은 인체의 자세유지를 담당하므로 쉽게 짧아질 수 있으며 이로 인해 신체의 유연성과 적절한 균형 유지 를 방해하고 무릎관절과 골반의 변형을 초래하여 바른 자세를 유지 할 수 없게 한다. ${ }^{4}$ 또한 오랜 시간 앉은 자세를 유지하는 현대인들에
게 다양한 상해를 유발한다. ${ }^{5}$ 뒤넙다리근은 앞굽힘을 하는 동안 허 리 굽힘을 증가시켜 척추의 상해 가능성이 높아지기 때문에 뒤넙다 리근의 조직 탄성 증가와 관절가동범위(range of motion, ROM) 향상 을 위한 스트레칭이 필요하며 스트레칭으로 인한 뒤넙다리근의 유연 성 증가를 통해 일상생활이나 운동 수행 시 상해 예방, 운동 능력 향 상 및 근 손상 방지에 효과적인 영향을 미칠 수 있게 된다. ${ }^{6.7}$

스트레칭은 근육의 신장을 통해 $\mathrm{ROM}$ 을 증가시키는 데 사용되는 치료법이다. ${ }^{89}$ 이는 최적의 근육 길이를 회복하기 위한 재활 프로그 램과 스포츠 활동의 핵심 요소이며 근육, 힘줄, 인대와 같은 연부조직 의 유연성 유지 및 향상에 도움을 준다.7.9 또한 스트레칭은 근육의 과 도한 긴장과 통증완화, 혈액순환 증가 그리고 호흡 순환 능력과 환경
Received Aug 19, 2019 Revised Sep 16, 2019

Accepted Sep 30, 2019

Corresponding author Hyoung Won Lim

E-mail movt12@hanmail.net
Copylight (C2019 The Korean Society of Physical Therapy

This is an Open Access article distribute under the terms of the Creative Commons Attribution Non-commercial License (Http:// creativecommons.org/license/by-nc/4.0.) which permits unrestricted non-commercial use, distribution, and reproduction in any medium, provided the original work is properly cited. 
적응 능력을 향상시킬 뿐만 아니라 근육의 유착을 방지하여 근 저항 을 감소시키며 일상 생활이나 스포츠 상해를 예방하고 운동 능력 향 상에 도움을 준다. 스트레칭 중 가장 많이 사용되는 기법인 정적 스 트레칭(static stretching, SS)은 근육을 최종 범위까지 가져간 다음 지 속적인 힘으로 오랜 시간 동안 이 위치에서 유지시키는 방법으로 근 육 길이를 가능한 길게 늘리기 위해 사용된다. ${ }^{10,11}$ SS가 부상률을 낮 추고 부상으로부터의 회복을 개선하는 데 도움이 된다는 선행연구 들의 보고가 있었으며 주당 3-5회 정도로 SS를 실시했을 때 ROM이 증가한다는 것이 입증되었다.9,12,13

Mulligan 기법은 통증이 없는 범위에서 능동적인 움직임을 반복하 여 수행하는 안전한 치료법으로, 이전의 연구들은 Mulligan 기법이 뒤넙다리근의 유연성을 향상시키는 데 효과적이라고 보고하였다.14,15 또한 연부조직의 염증 감소와 근이완을 유도하며 기능을 향상시킬 수 있다고 하였다. ${ }^{14}$ Mulligan의 two leg rotation (TLR)은 Mulligan 박사 가 개발한 기술로 뒤넙다리근 단축이 있는 환자, 뻗은발올림(straight leg raising, SLR) 시 제한이 있거나 통증이 있는 환자에게 시행되어지 고 있다. ${ }^{15}$ 또한 TLR은 통증 감각수용기의 부하를 줄여주고 증상을 감소시키며 ROM을 향상시킬 수 있다고 보고하였다. ${ }^{16}$ Yldırım 등근 뒤넙다리근의 유연성에 대한 효과적인 스트레칭 방법을 제시하기 위 해 SS, 고유수용성 신경근 촉진법(proprioceptive neuromuscular facilitation, PNF) 및 TLR 3가지 기법을 비교한 결과 PNF그룹과 TLR그룹 이 SS그룹보다 유연성이 유의하게 증가한 것으로 나타났다. 또 다른 연구에서는 TLR과 Mulligan의 bent leg raise (BLR)를 비교한 결과 두 기법 모두 뒤넙다리근의 유연성 증가에 효과적임을 보고하였다. ${ }^{6}$ 결 과적으로 TLR의 적용은 근육 신장 허용 범위의 변화와 뺏뺏함(stiffness) 감소 및 근육의 적응성 증가로 인해 뒤넙다리근이 길어지는 결 과를 낳을 수 있다고 보고하였다. ${ }^{6}$

기존의 선행연구에서 제시한 SS와 TLR은 치료사에 의해 수행되어 지는 방법이다.10,15 이에 반해 본 연구에서 비교하고자 하는 SS와 TLR 은 치료사나 외력의 필요 없이 대상자 스스로 수행 가능한 자가신장 방법(self-stretching)이다. 자가신장을 통한 두 스트레칭은 부상의 위 험이 적어 안전하며 시간이나 노력이 많이 들지 않아 쉽게 적용할 수 있다. 이는 유연성을 향상시키는 긍정적인 결과를 보여주므로 많이 사용되는 방법이다. ${ }^{8}$ 자가신장은 수축 활동 중에 세포질 칼슘이 증가 하여 근육 섬유 길이를 늘리는 데 효과적이다. ${ }^{18}$ 또한 관련된 근육의 제한 범위를 넘지 않아 무의식적으로 근육을 보호하여 근손상을 방 지할 수 있으며 상호 억제를 통해 길항근 수축을 완화할 수 있어 효 과적이라고 하였다. ${ }^{19.20}$ 따라서 본 연구에서는 이러한 자가신장의 장 점을 활용하여 뒤넙다리근의 유연성 향상에 효과적인 두 가지 스트 레칭 방법을 비교하고자 한다.

지금까지 뒤넙다리근의 유연성 향상을 위한 다양한 스트레칭 비
교 연구가 진행되었으나 대부분의 선행연구들은 기구 등을 이용한 SS의 효과에 대해서만 기술하였다..$^{10,11,13}$ 보조 없이 스스로 시행 가능 한 자가신장 방법에 대한 연구는 매우 부족한 실정이다. 또한 골반의 움직임까지 포함한 TLR과 SS를 자가신장을 통해 비교한 연구 역시 전무한 실정이다. 따라서 뒤넙다리근 단축 시 일상생활에서 쉽게 시 행할 수 있는 스트레칭 방법을 제시하기 위해 본 연구는 뒤넙다리근 이 단축된 성인에게 대상자 스스로 할 수 있는 SS와 TLR 적용 간에 유연성, $\mathrm{ROM}$, 그리고 통증에 미치는 영향을 조사하고자 한다.

\section{연구 방법}

\section{1. 연구대상}

본 연구는 천안 소재 D대학교에 재학 중인 대학생 30 명(남자: 10명, 여: 20 명)을 대상으로 각각 스스로 하는 SS를 시행한 실험군 13명, TLR을 적용한 실험군 14 명으로 두 그룹을 무작위로 나누어 진행하 였다. 2018년 12월 3일부터 21일까지 3주 동안 총 15회 실시하여 각각 의 스트레칭 기법을 적용하였다. 모든 대상자에게 연구의 목적과 절 차에 대해서 충분히 설명하였으며 실험에 자발적으로 참여할 것을 동의하였다. 연구 대상자들의 선정기준은 다음과 같다. 1) 엉덩관절 과 다리에 외상 및 수술 병력이 없는 자. 2) 실험 참여 시점에서 과거 6 개월 동안 다리관절에 활성 통증이 없는 자. 3) 양측 다리의 Backsaver sit and reach test 측정값 비교결과가 $0.5 \mathrm{~cm}$ 미만인 자. ${ }^{21}$ ) 중재 기간 동 안 측정한 앉아 윗몸 앞으로 굽히기 검사(sit and reach test, SRT) 값이 국민체력실태조사 기준에 따라 5 등급 이하(남자: $-4.9 \mathrm{~cm}$ 이하, 여: 1.6 $\mathrm{cm}$ 이하)인 자.22 실험을 중도 포기한 자와 기타 다리관절에 질환이 있 는 자는 제외하였다.

\section{2. 실험방법}

\section{1) 실험 절차}

본 연구는 뒤넙다리근이 짧아진 대상자에게 각각 SS와 TLR 적용 간 에 유연성, ROM, 그리고 통증에 미치는 영향을 비교하기 위해 다음 과 같은 절차로 실시하였다. 대상자 중 배제 기준에 따라 3 명이 제외 되었다. 본 연구에서는 27 명의 대상자를 각각 두 그룹으로 나누고 두 그룹 모두 중재 전과 후에 SRT, active 및 passive SLR을 총 2회 측정하 여 평균 값을 기록하였다. 시각통증등급(visual analogue scale, VAS)은 1 회 측정하여 기록하였다. 스트레칭은 3 주 동안 총 15 회 실행하였다. 연구자들은 대상자들에게 SRT 측정을 위해 양쪽 다리에 각각의 스 트레칭을 적용한 후 실시하였고, active 및 passive SLR 측정은 대상자 들의 일반적인 특성에 근거하여 우세측 다리를 기준으로 측정하였 다. 본 연구자들은 실험실 이외의 스트레칭은 종속 변인 결과에 영향 을 줄 수 있으므로 대상자에게 스트레칭을 삼가하도록 하였으며 각 
그룹의 실험실 온도는 $25^{\circ} \mathrm{C}$ 로 동일하게 설정하였다..$^{21}$

\section{2) 실험과정}

본 연구에서는 각각의 스트레칭에 대한 영상을 보여준 후 대상자마 다 3-5회 정도의 익숙화 과정(familization)을 가졌으며, 충분한 워밍업 을 실시하였다.

\section{(1) 정적 스트레칭(SS)}

본 연구에서는 30 초 동안 실시한 수동 및 자가신장 비교에서 자가신 장을 통한 SS가 유연성을 향상시키는 데 더 효과적이라는 이전 연구 를 토대로 대상자 스스로 스트레칭을 수행하였다. ${ }^{23} \mathrm{SS}$ 는 대상자를 바로 누운 자세에서 한쪽 다리를 굽힘하여 양손으로 오금 부위를 잡 게 하고 최대한 몸쪽으로 당겨 30 초간 유지하도록 하였다. ${ }^{24}$ 이때 엉 덩관절을 움직이지 않게 고정하고 반대쪽 다리는 굽혀지지 않도록 주의한다. 이어서 반대쪽 다리를 똑같은 방법으로 30초 스트레칭을 한 후 다리를 내려 30 초 동안 휴식을 취한다. 양쪽 다리에 각각 30 초 씩 스트레칭을 한 후 30 초 휴식을 취하도록 한다. ${ }^{25}$ 이를 1 세트로 정하 고 총 3 세트를 실시하여 전체 스트레칭 적용 시간은 4 분 30 초가 되도 록 하였다. 마지막 한 세트는 위 방법과 동일한 자세에서 무릎을 펴게 하고 이와 함께 발등 굽힘을 하여 스트레칭을 실시하도록 하였다 (Figure 1).

\section{(2) Mulligan's technique}

본 연구에서 사용한 Mulligan 기법인 two leg rotation (TLR)은 제3자 에 의한 스트레칭이 아닌 대상자 스스로 할 수 있는 자가신장 기술이 다. 대상자는 치료용 침대에서 바로 누운 자세로 대상자의 손은 각각 침대 양쪽 끝을 잡게 하고 양쪽 엉덩관절과 무릎관절을 굽힘하여 발 바닥 전체가 침대 바닥에 닿게 한다. 왼쪽 뒤넙다리근 스트레칭 시 대 상자는 왼쪽 침대 끝에 위치하여 어깨가 움직이지 않은 상태에서 몸 통과 발을 고정하고 검사자의 신호에 맞춰 왼쪽으로 무릎을 아래로 내리게 한다. 가동범위를 늘리기 위해 점차적으로 발바닥이 침대에 서 떨어지도록 한다(Figure 1). ${ }^{15}$ 최종 범위에서 3 초 동안 유지하고 제 자리로 돌아오게 하여 이를 5 번 반복한 후 오른쪽에도 동일한 방법 으로 시행하고 30 초 휴식을 취한다. ${ }^{6}$ 이를 1 세트로 정하고 총 3 세트를 실시하여 전체 스트레칭 적용 시간은 4 분 30 초가 되도록 하였다. 마 지막 세트에서는 발뒤꿈치를 침대 바닥에서 들어올린 상태로 시행하 도록 하였다.

\section{3) 측정도구}

(1) Sit and reach test (SRT)

SRT는 유연성 측정기(Yuxi Sports Goods Co., Ltd., China)를 사용하여 앉은 상태에서 두 다리를 가지런히 모으고 무릎은 편 상태에서 윗몸 은 바르게 세운다. 두 손은 나란히 붙이거나 겹치게 한 후 숨을 내쉬 면서 팔을 앞으로 최대한 멀리 뻗어 상체를 앞으로 숙인다. 두 손으로
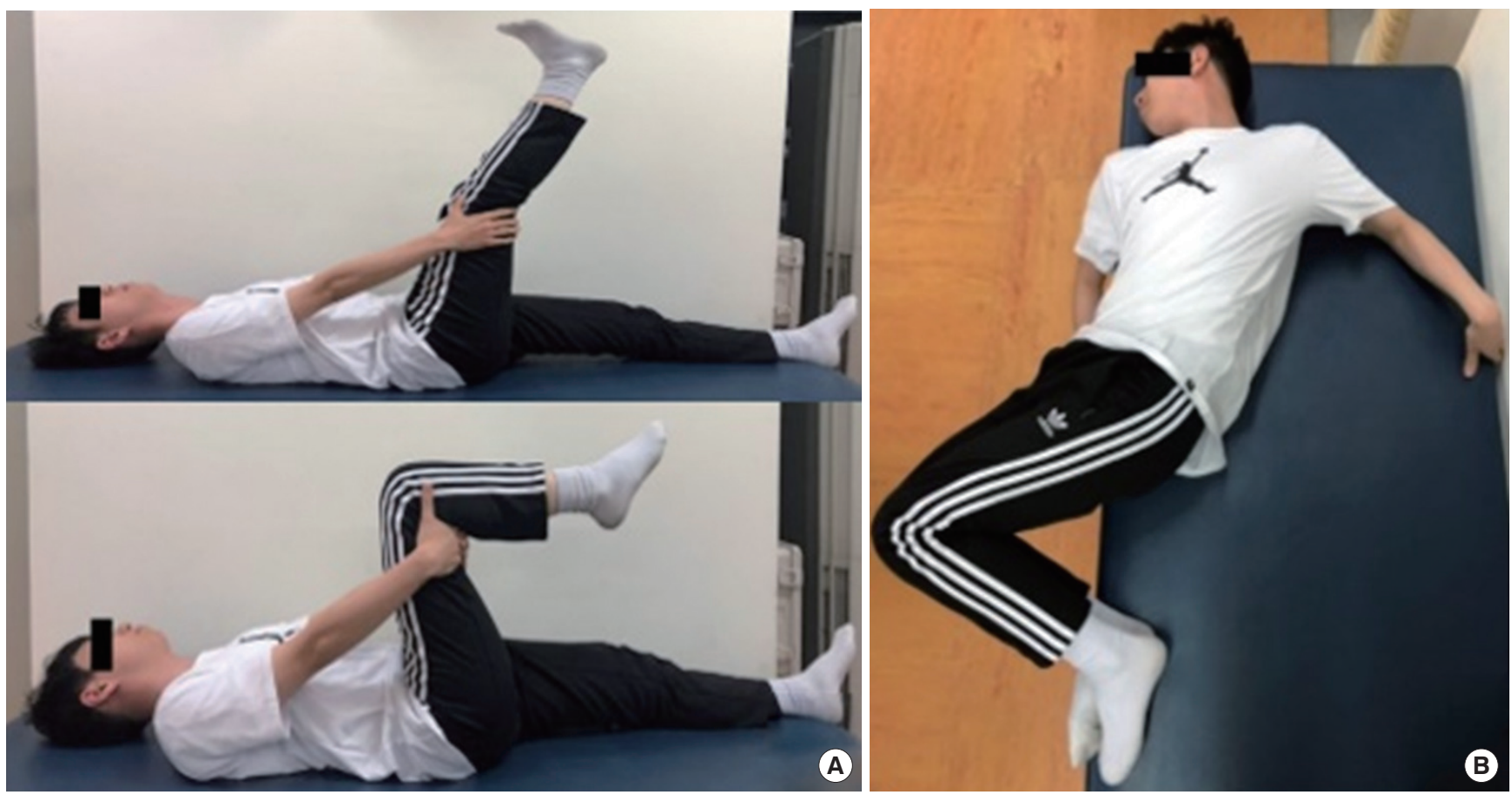

Figure 1. Intervention programs. (A) Static stretching, (B) Mulligan technique. 
눈금자를 앞으로 밀어 3 초간 유지하도록 하였다. 이때 검사자는 눈금 자를 기록하였다. SRT는 중간 정도의 타당도를 보이는 뒤넙다리근의 유연성 평가 도구이나 매우 실용적이고 사용이 간편한 유일한 실험 도구이다. ${ }^{26} \mathrm{SRT}$ 는 측정자 내 신뢰도 $(\mathrm{r}=0.46)$ 와 측정자 간 신뢰도 $(\mathrm{r}=0.67)$ 가 중간 정도로 보고되었다. ${ }^{27}$

(2) Active straight leg raise test (ASLR)

ASLR 측정은 대상자가 바로 누운 자세에서 머리와 몸통을 중립으로 위치시키고 무릎관절을 굽히지 않은 상태로 우세측 다리를 들어 올 리도록 하여 관절각도계(Goniometer, Medistore Co., Ltd., Korea)를 사 용해 엉덩관절 가동범위를 측정하였다. 대상자에게 통증 없이 유연 성이 허락하는 범위까지 다리를 들어올리도록 하였으며 검사자는 다리의 각도를 측정하였다. ASLR은 뒤넙다리근의 짧아짐을 평가하 기 위해 임상뿐만 아니라 스트레칭의 효과에 대한 연구에서도 흔히 사용되는 측정 방법이다. ${ }^{28}$

\section{(3) Passive straight leg raise test (PSLR)}

PSLR 측정은 검사자가 다리를 들어 올리는 동안에 무릎이 굽혀지지 않도록 한 손으로 고정을 하고 다른 한 손은 발목관절이 안쪽이나 바 깥쪽 돌림이 없는 중립 위치로 고정시키기 위해 발꿈치 힘줄 부위를 잡는다. ${ }^{29} \mathrm{ASLR}$ 과 동일하게 자세를 취하고 검사자는 대상자가 가동 범위의 제한 및 통증 호소 전까지 우세측 다리를 들어올리고 다른 검 사자에게 각도를 측정하도록 하였다.

(4) Visual analogue scale (VAS)

통증은 SRT, ASLR, PSLR 측정 간에 대상자 본인이 느꼈던 통증 정도
를 0 에서 10 까지의 범위에서 해당하는 위치에 스스로 표시하도록 하 였다. VAS는 측정자 내 신뢰도 $(r=0.96)$ 와 측정자 간 신뢰도 $(r=0.98)$ 가 높은 것으로 보고되었다. ${ }^{30}$

\section{3. 분석방법}

본 연구의 분석은 SPSS ver. 21.0 (SPSS Inc., IBM Co., Chicago, IL, USA) 통계프로그램을 이용하여 통계 처리하였다. 대상자의 일반적 특성에 대한 동질성 검사를 위해 독립 t-검정을 시행하였다. 측정 시점별 그 룹 내 전후 차이를 알아보기 위해 대응표본 $\mathrm{t}$-검정을 시행하였으며, 두 그룹 간 변화량의 차이를 알아보기 위하여 독립표본 $\mathrm{t}$-검정을 하 였다. 통계학적 유의성 검증을 위한 유의수준은 $\alpha=0.05$ 로 하였다.

\section{결 과}

\section{1. 연구 대상자의 일반적 특성}

연구 대상자는 총 27 명으로 SS 그룹에서 남자 4 명, 여자 9 명이었고 TLR 그룹에서 남자 5명, 여자 9명이었다. SS 그룹의 평균 연령은 22.31 \pm 1.7 세, 평균 신장은 $168.85 \pm 8.08 \mathrm{~cm}$, 평균 체중은 $65.69 \pm 12.52 \mathrm{~kg}$ 이었

Table 1. General characteristics of subjects

\begin{tabular}{llccc}
\hline & & SS $(\mathrm{N}=13)$ & TLR $(\mathrm{N}=14)$ & $\mathrm{p}$-value \\
\hline Sex & Male & 4 & 5 & $>0.05$ \\
& Female & 9 & 9 & \\
Age $(\mathrm{yr})$ & & $22.31 \pm 1.7$ & $22.43 \pm 2.06$ & \\
Height $(\mathrm{cm})$ & $168.85 \pm 8.08$ & $165.0 \pm 7.06$ & \\
Weight $(\mathrm{kg})$ & & $65.69 \pm 12.52$ & $66.21 \pm 14.10$ & \\
\hline
\end{tabular}

Mean \pm SD. SS: static stretching, TLR: two leg rotation

Table 2. Results of paired t-test to examine the pre-post intervention differences in SRT, ASLR, PSLR, and VAS in all 2 groups

\begin{tabular}{|c|c|c|c|c|c|c|}
\hline & & & & & & $n-1 a^{\prime}$ \\
\hline & & Mean \pm SD & $\mathrm{p}$-value & Mean \pm SD & $\mathrm{p}$-value & $p$-value \\
\hline $\mathrm{SRT}(\mathrm{cm})$ & Pre & $-2.44 \pm 6.71$ & $0.000^{*}$ & $-4.73 \pm 7.92$ & $0.000^{*}$ & 0.426 \\
\hline & Post & $5.35 \pm 5.01$ & & $7.19 \pm 6.55$ & & 0.423 \\
\hline & Variation & $7.80 \pm 3.93$ & & $11.93 \pm 5.49$ & & $0.035^{\star}$ \\
\hline $\operatorname{ASLR}\left({ }^{\circ}\right)$ & Pre & $60.00 \pm 7.64$ & $0.000^{*}$ & $55.36 \pm 5.36$ & $0.000^{*}$ & 0.078 \\
\hline & Post & $75.39 \pm 8.28$ & & $77.50 \pm 4.70$ & & 0.418 \\
\hline & Variation & $15.39 \pm 8.28$ & & $22.14 \pm 6.99$ & & $0.030^{*}$ \\
\hline $\operatorname{PSLR}\left({ }^{\circ}\right)$ & Pre & $68.08 \pm 9.47$ & $0.001^{*}$ & $66.07 \pm 9.03$ & $0.000^{*}$ & 0.578 \\
\hline & Post & $77.31 \pm 7.80$ & & $78.93 \pm 5.94$ & & 0.547 \\
\hline & Variation & $9.23 \pm 7.32$ & & $12.86 \pm 6.99$ & & 0.200 \\
\hline VAS (score) & Pre & $3.77 \pm 1.48$ & $0.001^{*}$ & $3.29 \pm 1.27$ & $0.000^{*}$ & 0.369 \\
\hline & Post & $2.61 \pm 1.04$ & & $1.93 \pm 1.00$ & & 0.093 \\
\hline & Variation & $-1.15 \pm 0.90$ & & $-1.36 \pm 0.63$ & & 0.501 \\
\hline
\end{tabular}

Mean \pm SD. SS: static stretching, TLR: two leg rotation, SRT: sit and reach test, ASLR: active straight leg raising test, PSLR: passive straight leg raising test, VAS: visual analogue scale.

${ }^{*} p<0.05$. 
다. TLR 그룹의 평균 연령은 $22.43 \pm 2.06$ 세, 평균 신장은 $165.0 \pm 7.06 \mathrm{~cm}$, 평균 체중은 $66.21 \pm 14.10 \mathrm{~kg}$ 이었다. 두 그룹의 일반적 특성에 대해 동 질성 검정을 실시한 결과 모두 유의한 차이가 없었다( $p>0.05$ )(Table 1).

\section{Sit and reach test 길이 비교}

SS 그룹과 TLR 그룹의 스트레칭 전후 SRT 측정 길이와 변화량의 분 석결과는 Table 2와 같다. SS 그룹과 TLR 그룹 모두 측정 시점별 집단 내 차이가 있었으나 $(\mathrm{p}<0.05)$ 집단 간 유의한 차이는 없었다 $(\mathrm{p}>0.05)$. SS 그룹보다 TLR 그룹에서 SRT 변화량 값이 더 컸으며 통계적으로 유의하였다 $(\mathrm{p}<0.05)$.

\section{Active straight leg raise test 측정 각도 비교}

SS 그룹과 TLR 그룹의 스트레칭 전후 ASLR 측정 각도와 변화량의 분 석결과는 Table 2 와 같다. SS 그룹과 TLR 그룹 모두 측정 시점별 집단 내 차이가 있었으나 $(\mathrm{p}<0.05)$ 집단 간 유의한 차이는 없었다 $(\mathrm{p}>0.05)$. SS 그룹보다 TLR 그룹에서 ASLR 변화량 값이 더 컸으며 통계적으로 유의하였다 $(\mathrm{p}<0.05)$.

\section{Passive straight leg raise test 측정 각도 비교}

SS 그룹과 TLR 그룹의 스트레칭 전후 PSLR 측정 각도와 변화량의 분 석결과는 Table 2 와 같다. SS 그룹과 TLR 그룹 모두 측정 시점별 집단 내 차이가 있었으나 $(\mathrm{p}<0.05)$ 집단 간 유의한 차이는 없었다 $(\mathrm{p}>0.05)$. PSLR 변화량에 대한 집단 간 비교에서 유의한 차이가 없었다 $(\mathrm{p}>0.05)$.

\section{Visual analogue scale 측정 점수 비교}

SS 그룹과 TLR 그룹의 스트레칭 전후 VAS 측정 점수 비교는 Table 2 와같다. SS 그룹과 TLR 그룹 모두 측정 시점별 집단 내차이가 있었으 나 $(\mathrm{p}<0.05)$ 집단 간의 유의한 차이는 없었다 $(\mathrm{p}>0.05)$. VAS 변화량에 대한 집단간 비교에서 유의한 차이가 없었다 $(\mathrm{p}>0.05)$.

\section{고 찰}

본 연구에서는 뒤넙다리근이 짧은 성인에게 일반적으로 적용되는 SS 와 Mulligan 기법 중 하나인 TLR을 피험자 스스로 시행했을 때 각 그 룹 간의 유연성, ROM, 그리고 통증에 미치는 영향을 조사하고자 하 였다.

본 연구 결과 SRT 측정 값은 SS 그룹과 TLR 그룹 모두 측정 시점별 집단 내 유의한 차이가 있었으며, 집단 간 변화량은 TLR 그룹에서 SRT 변화량 값이 더 컸으며 유의한 차이가 있었다. SRT는 허리 및 엉 덩관절의 유연성을 평가하는 데 적절하며 높은 신뢰성을 보인다고
보고하였다. ${ }^{31,32}$ 본 연구의 SS 그룹에서 SRT 값의 증가는 정적 스트레 칭 적용 후 뒤넙다리근의 짧아짐이 감소했다고 보고한 이전의 선행 연구와 유사한 결과로 나타났다. ${ }^{33}$ 반면, TLR 그룹은 SS 그룹과 달리 엉덩관절 돌림 움직임으로 인하여 직접적으로 근육방추의 Ia 구심성 신경섬유를 자극하지 않아 활동을 감소시키고 이와 함께 골지힘줄기 관의 활성화로 인하여 근이완을 유도했기 때문에 집단 간 변화량에 서 유의한 차이를 보였다고 생각된다. ${ }^{17}$ 또한 SS은 엉덩관절을 고정한 상태로 스트레칭하여 뒤넙다리근의 먼쪽 부분만 늘어나게 되지만 TLR은 고정하지 않은 상태로 시행하여 엉덩관절 가동범위가 늘어나 기 때문에 SS보다 TLR이 뒤넙다리근의 유연성 향상에 효과적이라고 사료된다.

ASLR 측정 각도 값은 두 그룹 모두에서 측정 시점별 집단 내 유의 한 차이가 있었으며, 집단 간 변화량은 TLR 그룹에서 ASLR 변화량 값이 더 컸으며 유의한 차이를 보였다. SLR은 뒤넙다리근의 기능을 향상시키기 위한 운동 프로그램의 효과를 검사하고 최적의 운동 성 과와 유연성 변화를 결정하기 위해 사용될 수 있다고 하였으나, 신경 학적 조직을 포함한 다리의 깊은 근막 및 골반의 연부조직과 같은 뒤 넙다리근 이외의 구조에 의해 제한될 수 있다고 하였다. ${ }^{34,35}$ 이전의 많 은 연구 결과에 따르면, 뒤넙다리근에 대한 SS가 SLR 각도와 근육의 길이를 증가시킨다고 하였으며, 이러한 ROM 증가는 뒤넙다리근의 신장 허용 범위가 증가했기 때문이라고 보고하였다.36-38 반면 ASLR은 골반의 움직임과 관련이 있다. 뒤넙다리근의 짧아짐은 골반 뒤쪽 기 울임을 유도하고 이로 인해 발생하는 비정상적인 허리골반 협응패턴 은 척추 하중을 증가시켜 요통을 유발한다고 하였다. ${ }^{39}$ 이때 뒤넙다 리근의 길이 증가는 척추 골반 운동과 골반의 과도한 뒤쪽 기울임을 개선시켜 효율적인 허리골반 리듬(Lumbopelvic rhythm, LPR)을 제공 한다고 하였다. ${ }^{15,40} \mathrm{LPR}$ 의 안정화는 다양한 스포츠 상황에서 하체 손 상의 발생을 낮추거나 다리의 생체역학적 기능을 향상시킬 수 있다 고 보고하였다. ${ }^{41}$ Scholtes 등 ${ }^{42}$ 은 엉덩관절 안쪽, 바깥쪽 돌림 근육의 신장운동과 허리골반의 안정성 운동이 허리골반의 과도한 움직임을 감소시킨다고 보고하였다. Pratik 등15은 급성 허리통증 환자를 대상 으로 뒤넙다리근 유연성에서 TLR의 효과에 대한 연구를 시행한 결 과, TLR이 통증, 가동범위 및 기능 장애 측면에서 효과적이라고 하였 다. 상기 선행연구를 통해 볼 때 본 연구에서 TLR 그룹의 ASLR 변화 량에 유의한차이가 있었던 것은 엉덩관절 안쪽, 바깥쪽 돌림 근육의 신장을 통해 뒤넙다리근의 유연성 증가로 골반의 과도한 뒤쪽 기울 임을 개선시켜 효율적인 LPR을 제공하였기 때문이라고 사료된다.

PSLR 측정값은 두 그룹 모두에서 측정 시점별 집단 간과 변화량에 유의한 차이가 없었다. 본 연구 결과 PSLR 측정값은 중재 후 SS 그룹 에서 9.23 \pm 7.32 점, TLR 그룹에서 $12.86 \pm 6.99$ 점만큼 증가하였다. 그룹 내 전후 PSLR 값이 유의한 차이를 보였던 이유로는 신장되는 근육힘 
줄단위의 기계적 및 생리적 변화와 스트레칭 허용 범위 증가 때문이 라고 추정된다. ${ }^{43}$ 또한 중재 후 통계적으로 유의하지 않았던 이유로는 두 그룹의 피험자들은 모두 짧아짐이나 구축으로 인한 PROM의 제 한범위가 크지 않았기 때문에 PSLR 변화량의 유의한 차이가 없었던 것으로 사료된다.

본 연구 결과 그룹 내 전후 VAS 값이 유의한차이를 보였으며, 이는 스트레칭 적용 후 근육과 관절에서의 구심성 정보가 통각수용기의 신호를 방해하여 통증에 대한 인식을 억제하였기 때문으로 생각된 다. ${ }^{44}$ 또한 VAS 측정값은 중재 후 SS 그룹에서 $1.15 \pm 0.90$ 점, TLR 그룹 에서 $1.36 \pm 0.63$ 점만큼 감소하였으나 두 그룹 모두에서 측정 시점별 집단 간과 변화량에 유의한 차이가 없었다. 이러한 이유로는 두 그룹 의 피험자들은 비교적으로 관절가동범위의 제한이 적고 경한 통증 을 보여 통계적으로 유의한 차이가 없었던 것으로 사료된다. 통계적 으로 유의한 차이는 없었으나 SS보다 큰 VAS 값의 감소를 보인 TLR 은 골반 회전을 동반하여 뒤넙다리근의 유연성을 향상시킬 수 있었 으며, 스트레칭에 따른 뒤넙다리근의 기계적 변화로 인해 근육 신장 허용범위의 변화가 생겨 통증을 더 많이 완화시킬 수 있었다고 사료 된다. ${ }^{15}$

이상의 결과를 종합해 볼 때 뒤넙다리근이 짧아진 성인에게 적용 한 SS와 TLR 모두 유연성 향상에 효과적이었으나 부상의 위험도가 적으며, 골반의 돌림 움직임을 동반하여 신체 전반적인 안정화를 도 모하는 TLR이 SS보다 효과적이었음을 보여준다.

본 연구의 제한점은 다음과 같다. 첫째, 연구 대상자의 연령이 20대 로 국한된 점과 표본 수가 적어 연구 결과를 일반화하기 어렵다는 것 이다. 둘째, 짧은 중재 기간 동안 수행되어 장기적인 효과를 알기 어려 웠으며, 중재 기간 동안 실험에 영향을 미칠 수 있는 대상자의 일상생 활을 철저히 통제하지 못하였다는 것이다. 셋째, 스트레칭 적용 시 결 과에 영향을 줄 수 있는 허리 및 골반에 대한 연구가 부족했다. 이러 한 제한점에도 불구하고 본 연구 결과는 근육 이완에 효과적인 자가 신장 방법으로 TLR의 효과를 보고한 최초의 연구라는 데 의의가 있 다. 향후 연구에서는 허리 및 골반 등 다양한 요인에 대한 분석이 필 요하며, 뒤넙다리근이 짧아진 성인들에게 SS와 TLR뿐만 아니라 다 양한 중재에 관한 연구가 이루어져야 할 것이다.

\section{결 론}

짧아진 뒤넙다리근에 SS와 TLR 적용 후 중재 효과를 조사한 결과 SRT, ASLR에서 두 집단 모두 집단 간의 비교에서 변화량에 유의한 차 이가 있었다. 이러한 연구 결과를 보았을 때 TLR은 SRT, ASLR의 변화 에 긍정적인 효과를 보이며 TLR을 통해 복부근육 활성화, LPR 안정 화, 근육의 뻣뻣함 감소와 통증 감소에 효과적이라는 것을 알 수 있
다. 따라서 TLR이 뒤넙다리근의 유연성을 향상시켜 일상생활이나 스 포츠 활동에서 손상을 예방하고, 근육의 이완을 가능하게 하며 척추 의 부상 위험 감소에 효과적인 자가신장 방법이라고 사료된다.

\section{REFERRENCES}

1. Emlund L, Vieira LA. Hamstring injuries: update article. Rev Bras Ortop. 2017;52(4):373-82.

2. Chapman AE, Caldwell GE. Kinetic limitations of maximal sprinting speed. J Biomech. 1983;16(1):79-83.

3. Thelen DG, Chumanov ES, Hoerth DM et al. Hamstring muscle kinematics during treadmill sprinting. Med Sci Sports Exerc. 2005;37(1): 108-14.

4. Croisier JL. Factors associated with recurrent hamstring injuries. Sports Med. 2004;34(10):681-95.

5. Kisner C, Colby LA. Therapeutic exercise: foundations and techniques. 6th ed. Philadelphia, Fa Davis. 2012.

6. Rajalaxmi. V, Veena. S. Effectiveness of mulligan's two leg raise and bent leg raise techniques in subjects with acute non-specific low back pain in improving hamstring flexibility. Int J Physiother Res. 2015;1(2):29-36.

7. Park HY, Lee MM. A comparison of the effect of stretching technique on hamstring muscle for flexibility, strength, pressure pain threshold value and muscle tone. J Korean Soc Phys Med. 2017;12(4):39-46.

8. Medeiros DM, Cini A, Sbruzzi G. Influence of static stretching on hamstring flexibility in healthy young adults: Systematic review and metaanalysis. Physiother Theory Pract. 2016;32(6):438-45.

9. Malliaropoulos N, Papalexandris S, Papalada A et al. The role of stretching in rehabilitation of hamstring injuries: 80 athletes follow-up. Med Sci Sports Exerc. 2004;36(5):756-9.

10. Stephens J, Davidson J, Derosa J et al. Lengthening the hamstring muscles without stretching using "awareness through movement". Phys Ther. 2006;86(12):1641-50.

11. Puentedura EJ, Huijbregts PA, Celeste $S$ et al. Immediate effects of quantified hamstring stretching: Hold-relax proprioceptive neuromuscular facilitation versus static stretching. Phys Ther Sport. 2011;12(3): 122-6.

12. Smith CA. The Warm-up Procedure: To Stretch or not to Stretch. A Brief Review. J Orthop Sports Phys Ther. 1994;19(1):12-7.

13. Cross KM, Worrell TW. Effects of a Static Stretching Program on the Incidence of Lower Extremity Musculotendinous Strains. J Athl Train. 1999;34(1):11-4.

14. Mulligan BR. Manual Therapy: Nags, Snags, MWMs, etc. 6th ed. Plane View Services;2010.853-6.

15. Phansopkar PA, Kage V. Effect of Mulligan's two leg rotation technique on hamstring flexibility in subjects with acute nonspecific low back pain: clinical trial. J Med Res. 2014;2(6):70-8.

16. Kumar SP. Cherian PJ. Efficacy of spinal mobilization in the treatment of patients with lumbar radiculopathy due to disc herniation: a randomized clinical trial. Int J NNS. 2011;3(2):65-76.

17. Yildırım MS, Ozyurek S, Tosun O et al. Comparison of effects of static, proprioceptive neuromuscular facilitation and Mulligan stretching on hip flexion range of motion: a randomized controlled trial. Biol Sport. 
2016;33(1):89-94.

18. Riley DA, Van Dyke JM. The effects of active and passive stretching on muscle length. Phys Med Rehabil Clin N Am. 2012;23(1):51-7.

19. Simic L, Sarabon N, Markovic G. Does pre-exercise static stretching inhibit maximal muscular performance? A meta-analytical review. Scand J Med Sci Sports. 2013;23(2):131-48.

20. Winters MV, Blake CG, Trost JS et al. Passive versus active stretching of hip flexor muscles in subjects with limited hip extension: a randomized clinical trial. Phys Ther. 2004;84(9):800-7.

21. López-Miñarro PA, Andújar PS, Rodrñguez-Garcña PL. A comparison of the sit-and-reach test and the back-saver sit-and-reach test in university students. J Sports Sci Med. 2009;8(1):116-22.

22. Korea institute of sports science. The Survey of National Physical Fitness. Seoul. Ministry of Culture Scports and Tourism. 2017:175.

23. Divan MA, Bilques S. Efficacy of active stretching in improving the hamstring flexibility. Int J Physiother Res. 2014;2(5):725-32.

24. Handy WD, lrion JM. The effect of time on static stretch on the flexibility of the hamstring muscle. Phy Ther. 1994;74:845-50.

25. Walsh GS. Effect of static and dynamic muscle stretching as part of warm up procedures on knee joint proprioception and strength. Hum Mov Sci. 2017;55:189-95.

26. Jackson AW, Morrow JR Jr, Brill PA et al. Relations of sit-up and sit-andreach tests to low back pain in adults. J Orthop Sports Phys Ther. 1998;27(1):22-6.

27. Mayorga-vega D, Merino-Marban R, Viciana J. Criterion-related validity of sit-and-reach tests for estimating hamstring and lumbar extensibility: a meta-analysis. J Sports Sci Med. 2014;13(1):1-14.

28. Herrington L, Bendix K, Cornwell C et al. What is the normal response to structural differentiation within the slump and straight leg raise tests? Man Ther. 2008;13(4):289-94.

29. Ylinen JJ, Kautiainen HJ, Hakkinen AH. Comparison of active, manual, and instrumental straight leg raise in measuring hamstring extensibility. J Strength Cond Res. 2010;24(4):972-7.

30. Bijur PE, Silver W, Gallagher EJ. Reliability of the visual analog scale for measurement of acute pain. Acad Emerg Med. 2001;8(12):1153-7.

31. Muyor JM, Zemková E, Štefániková G et al. Concurrent validity of clinical tests for measuring hamstring flexibility in school age children. Int J Sports Med. 2014:35(8):664-9.

32. Morcelli MH, Oliveira JM CA, Navega MT. Comparison of static, ballis- tic and contract-relax stretching in hamstring muscle. Fisioter. Pesqui. 2013;20(3):244-9.

33. Odunaiya NA, Hamzat TK, Ajayi OF. The effects of static stretch duration on the flexibility of hamstring muscles. Afr J Biomed Res. 2005; 8(2):79-82.

34. Gajdosik RL. Effects of static stretching on the maximal length and resistance to passive stretch of short hamstring muscles. J Orthop Sports Phys Ther. 1991;14(6):250-5.

35. Bohannon R, Gajdosik R, LeVeau BF. Contribution of pelvic and lower limb motion to increases in the angle of passive straight leg raising. Phys Ther. 1985;65(4):474-6.

36. Godges JJ, Macrae H, Longdon C et al. The effects of two stretching procedures on hip range of motion and gait economy. J Orthop Sports Phys Ther. 1989;10(9):350-7.

37. Hubley CL, Kozey JW, Stanish WD. The effects of static stretching exercises and stationary cycling on range of motion at the hip joint. J Orthop Sports Phys Ther. 1984;6(2):104-9.

38. Moore MA, Hutton RS. Electromyographic investigation of muscle stretching techniques. Med Sci Sports Exerc. 1980;12(5):322-9.

39. Gajdosik RL, Hatcher CK, Whitsell S. Influence of short hamstring muscles on the pelvis and lumbar spine in standing and during the toe-touch test. Clin Biomech (Bristol, Avon). 1992;7(1):38-42

40. Jandre Reis FJ, Macedo AR. Influence of hamstring tightness in pelvic, lumbar and trunk range of motion in low back pain and asymptomatic volunteers during forward bending. Asian Spine J. 2015;9(4):535-40.

41. Chaudhari AM, McKenzie CS, Pan X et al. Lumbopelvic control and days missed because of injury in professional baseball pitchers. Am J Sports Med. 2014;42(11);2734-40.

42. Scholtes SA, Norton BJ, Lang CE et al. The effect of within-session instruction on lumbopelvic motion during a lower limb movement in people with and people without low back pain. Man Ther. 2010;15(5): 496-501.

43. Ayala F, Sainz de Baranda P, De Ste Croix M et al. Comparison of active stretching technique in males with normal and limited hamstring flexibility. Phys Ther Sport. 2013;14(2);98-104.

44. Mhatre BS, Singh Y, Tembhekar JY. Which is the better method to improve "perceived hamstrings tightness"-Exercises targeting neural tissue mobility or exercises targeting hamstring muscle extensibility?. Int J Ost Med. 2013;16(3):153-62. 